\title{
LATAR BELAKANG INDONESIA MENERIMA PENGUNGSI ROHINGYA PADA TAHUN 2015 (ANALISA KONSTRUKTIVIS)
}

\author{
Lay Yang Moy, Ardli Johan Kusuma \\ Universitas 17 Agustus 1945 Jakarta \\ layyangmoy@gmail.com,ardli.johan@yahoo.com
}

\begin{abstract}
Prolonged military conflict between the government of Myanmar and Rohingya ethnicity has affected to the neighboring countries, particularly Southeast Asia. Indonesia is one of those affected by exodus of Rohingya ethnicity refugees to Southeast Asia in May 2015. Boats of the refugee exodus tottering in the middle of the sea after left by people smuggler were finally stranded in the Strait of Malacca. The coming of the refugees was rejected by three countries including Indonesia, Malaysia, and Thailand. The Army increased their surveillance and dispelled the boats from entering to sovereignty territory of the Republic of Indonesia, however, the community of Aceh who uphold the Human Right values, felt a pity with condition of the refugees and immediately gave a help and bought them to the land. After were criticized by local and international people due to their refusal to the refugees from Myanmar, finally the three countries made a consultation meeting. Indonesia and Malaysia stated to welcome the refugees of Rohingya ethnicity for one year.

This research was aimed at analyzing change of Indonesian stance toward the coming of Rohingya ethnicity refugees from Myanmar in the middle of May 2015. The change of Indonesian stance from rejecting the coming of Rohingya ethnicity with many reasons to accept them for a year was the main problem of study in this research. The problem was analyzed by using qualitative descriptive method with constructivism paradigm as the argument basis and was strengthen by concept of refugees and Human Right values (HAM).

Based on the finding of this research, it is concluded that the change of Indonesian stance from refusing to be accepting the Rohingya ethnicity refugees was due to insistence of local and international people as well as Indonesian identity as a country upholding Human Right values.
\end{abstract}

Keyword: Indonesia, refugees, Rohingya ethnicity, Human Right values.

\begin{abstract}
ABSTRAK
Kehadiran gelombang pengungsi etnis Rohingya yang mencari suaka ke wilayah Asia Tenggara, menimbulkan polemik. Kapal-kapal eksodus para pengungsi etnis Rohingya yang terombang-ambing di tengah laut setelah ditinggalkan oleh para penyelundup manusia, terdampar di perairan dekat Selat Malaka. Kehadiran para pengungsi tersebut ditolak oleh tiga negara : Indonesia, Malaysia dan Thailand. TNI meningkatkan pengawasan dan menghalau kapal-kapal para pengungsi yang memasuki wilayah kedaulatan RI, namun masyarakat Aceh merasa iba melihat kondisi para
\end{abstract}


pengungsi dan segera membawa para pengungsi ke darat. Setelah mendapat kecaman dari lokal dan internasional karena menolak para pengungsi asal Myanmar tersebut, akhirnya Indonesia dan Malaysia menyatakan bersedia menampung para pengungsi asal Rohingya selama satu tahun.

Penelitian ini menelaah perubahan sikap Indonesia yang semula menolak dengan berbagai alasan, akhirnya bersedia menampung para pengungsi etnis Rohingya selama satu tahun. Permasalahan tersebut dianalisis menggunakan metode deskripsi kualitatif dengan paradigma konstruktivisme sebagai dasar argumen dan diperkuat dengan konsep pengungsi (refugees).

Berdasarkan temuan hasil penelitian, diperoleh kesimpulan bahwa perubahan sikap Indonesia yang akhirnya bersedia menerima para pengungsi etnis Rohingya dikarenakan identitas Indonesia sebagai negara yang menjunjung tinggi norma HAM.

Kata Kunci : Indonesia, pengungsi, etnis Rohingya, identitas, norma HAM.

\section{Pendahuluan}

Munculnya kembali gelombang pengungsi etnis Rohingya dan Bangladesh asal Myanmar di perairan Selat Malaka pada pertengahan bulan Mei tahun 2015, menimbulkan masalah baru bagi negara-negara di sekitarnya. Menurut data UNHCR, diperkirakan masih ada 6000 sampai 8000 imigran asal Bangladesh dan etnis Rohingya yang terkatung-katung di perairan laut Andaman dan Selat Malaka. ${ }^{1}$ Kehadiran kapal-kapal para pengungsi tersebut ditolak oleh tiga negara di sekitar Selat Malaka, yakni : Malaysia, Thailand dan Indonesia. Indonesia melalui TNI langsung memperkuat siaganya di perairan dekat Aceh dan berupaya keras untuk menghalangi kapal-kapal yang membawa para pengungsi agar tidak memasuki wilayah kedaulatan RI, selain itu TNI juga melarang para nelayan di Aceh agar tidak menjemput dan membawa para pengungsi yang terobang-ambing di laut untuk naik ke darat. Di saat yang bersamaan, para nelayan dan warga Aceh yang tidak menghiraukan TNI, malah menolong ratusan pengungsi etnis Rohingya dan Bangladesh yang terombang-ambing di tengah laut. Gelombang pengungsi tersebut bukanlah yang pertama kali, sebelumnya hampir 600 pengungsi terdampar di Lhoksukon dan kini menempati lokasi pengungsian di Aceh Utara. ${ }^{2}$ Saat ditemukan, para pengungsi dalam kondisi kritis karena kelaparan dan

\footnotetext{
${ }^{1}$ Ahmad Hatim Benarfa, 2015, Di Selat Malaka, Masih 8000-an Pengungsi Masih Terkatung katung, diakses dari http://www.Teropong-senayan.com/10725-di-selat-malaka-masih-8000-anpengungsi-masih-terkatung katung/, pada tanggal 6 Oktober 2015 pukul 12.00 WIB.

2 Linda Trianita, 2015, Pemerintah Akan Pulangkan Pengungsi Rohingya, diakses dari http://nasional.tempo.co/read/news/201 5/05/19/058667533/pemerintah-akan-pulangkanpengungsi-rohingya, pada tanggal 6 Oktober 2015 pukul 8.00 WIB.
} 
dehidrasi setelah kapal rusak tak bermesin yang ditumpangi oleh para pengungsi asal Bangladesh dan Etnis Rohingya tersebut kehabisan logistik dan terombang ambing di tengah laut.

Atas sikap penolakan tersebut, pemerintah Indonesia mendapat kecaman dari lokal dan internasional. Indonesia, Malaysia dan Thailand kemudian mengadakan rapat konsultasi di Putrajaya (Malaysia), dalam perundingan tersebut, Indonesia dan Malaysia akhirnya sepakat untuk memberikan bantuan kemanusiaan kepada 7000 imigran gelap yang masih terkatung-katung di sekitar Selat Malaka, agar di beri tempat penampungan sementara berjangka waktu satu tahun. ${ }^{3}$ Indonesia juga mengajak negara-negara lain agar berpartisipasi dalam upaya penanggulangan pengungsi Rohingya. ${ }^{4}$ Menurut Kementerian Luar Negeri Republik Indonesia total ada 1.346 pengungsi dari Myanmar dan Bangladeh yang masuk ke perairan Indonesia pada bulan Mei 2015. Para pengungsi ditampung di dua tempat wilayah Aceh. Kedatangan gelombang pertama sebanyak 558 pengungsi, lalu disusul dengan tiga gelombang kedatangan berikutnya masing-masing 664 orang, 47 orang, dan 96 orang. $^{5}$

Atas bantuan dan kesediaan untuk menampung sementara bagi pengungsi Rohingya, UNHCR (Komisi Tinggi PBB untuk menangani pengungsi) di Jenewa mengapresiasi niat Indonesia dan Malaysia. Berdasarkan fenomena perubahan sikap Indonesia, muncullah pertanyaan : Mengapa Indonesia bersedia pengungsi Rohingya pada tahun 2015 ?

Penulisan ini ingin melihat bahwa pandangan dari para tokoh konstruktivis seperti Alexander Wendt, Martha Finnemore dan Kathryn Sikkink tentang norma HAM internasional (struktur) yang mempengaruhi Indonesia (agen), sehingga Indonesia yang semula menolak kehadiran para pengungsi, menjadi bersedia menampung para pengungsi.

\footnotetext{
3 Malaysia dan Indonesia Setuju Tampung Pengungsi Rohingya, 2015, diakses dari http://www.dw.com/id/ malaysia-dan-indonesia-setuju-tampung-pengungsi-rohingya/a-18462889/, pada tanggal 6 Oktober 2015 pukul 8.00 WIB.

4 Ibid

5 Kedatangan 1.346 pengungsi Rohingya, pemerintah percepat resettlement, 2015, diakses dari http://www.rappler.com/world/regions/asia-pacific/indonesia/bahasa/93694-kedatanganpengungsi-rohingya-pemerintah-percepat resetlement, pada tanggal 6 Oktober 2015, pukul 8.00 WIB.
} 


\section{Metode.}

Metode yang dipakai adalah kualitatif deskriptif yang bertujuan untuk mendiskriptifkan, mencatat, analisis, dan menginterpretasikan fenomena atau keadaan saat kedatangan pengungsi etnis Rohingya di Aceh pada bulan Mei 2015. Untuk memberikan analisis eksplanatif, maka penulis menempatkan 'sikap pemerintah Indonesia' sebagai variabel dependen, sedangkan 'norma HAM' sebagai variabel independen.

\section{Kerangka Pemikiran.}

\section{A. Konsep Refugees (Pengungsi).}

Dalam Kamus Besar Bahasa Indonesia, akar kata dari pengungsi adalah ungsi dan kata kerjanya adalah mengungsi, yaitu pergi mengungsi (menyingkirkan) diri dari bahaya atau menyelamatkan diri (ke tempat yang memberikan rasa aman), pengungsi adalah orang / penduduk yang mengungsi atau pindah ke negara lain karena aliran politik yang bertentangan dengan politik penguasa negara asalnya. ${ }^{6}$

Menurut Konvensi UN 1951 pasal 1 tentang status pengungsi ${ }^{7}$, adalah:

" A refugee is someone who has been forced to flee his or her country because of persecution, war, or violence. A refugee has a well-founded fear of persecution for reasons of race, religion, nationality, political opinion or membership in a particular social group. Most likely, they cannot return home or are afraid to do so. War and ethnic, tribal and religious violence are leading causes of refugees fleeing their countries".

Berdasarkan definisi di atas, dapat disimpulkan bahwa pengungsian bertujuan untuk mengamankan diri karena adanya bahaya yang mengancam jiwa, karena adanya bencana buatan manusia (man made disaster). Mengungsi dapat dilakukan dalam lingkup satu wilayah negara atau ke negara lain karena adanya konflik

\footnotetext{
${ }^{6}$ Kamus Besar Bahasa Indonesia, Departemen Pendidikan dan Kebudayaan, Jakarta: Balai Pustaka, 1995, hlm. 657.

7 What is a refugee, diakses dari http://www.unhcr.or.id/id/siapa-yang-kamibantu/pengungsi, pada tanggal 10 November 2015 pukul 12.00 WIB.
} 
politik. ${ }^{8}$ Hal ini sama dengan pengungsi etnis Rohingya yang eksodus dari wilayahnya untuk menyelamatkan diri karena adanya tindakan anarki dan intimidasi serta pembantaian yang disebabkan konflik bersenjata.

\section{B. Paradigma Konstruktivisme}

Untuk menjawab rumusan permasalahan yang telah dipaparkan sebelumnya, yakni : "Mengapa Indonesia bersedia menerima para pengungsi Rohingya pada tahun 2015 ? , penulis akan mengaplikasikan paradigma konstruktivis yang mementingkan faktor non-material (ideational factor) seperti : ide, nilai, norma dan budaya yang tidak diakomodasi oleh pendekatan realisme dan liberalisme. ${ }^{9}$ Konstruktivis lebih melihat pada interaksi sosial yang terwujud dalam shared ideas/pemahaman intersubyektif yang mempengaruhi. Dalam penelitian ini, penulis mengunakan pendapat dari beberapa tokoh konstruktivis yakni Alexander Wendt. Wendt sendiri menyebut konstruktivisme sebagai "structural idealism"10. Wendt mengemukakan bahwa: "Identities and interests of actors are constructed by these shared ideas rather than given by nature". "Shared ideas, sebagai dalam pandangan konstruktivisme adalah yang membentuk identitas. Pembentukan identitas sebagian besar dilakukan oleh sekelompok elit pembuat kebijakan, namun pembentukan identitas tersebut merupakan respon terhadap shared ideas/pemahaman intersubyektivitas, yang dianalogikan oleh Wendt sbb.: ${ }^{12}$

'Jika masyarakat 'lupa' apa yang dinamakan universitas, maka kekuasaan dan kegiatan profesor serta mahasiswa menjadi tidak lagi eksis; demikian juga ketika Amerika Serikat dan Uni Sovyet memutuskan bahwa mereka tidak lagi musuh, maka Perang Dingin akan usai”.

Identitas akan didapat oleh aktor dengan keikutsertaannya dalam pembentukan shared ideas/pemahaman intersubyektivitas tersebut. Identitas

\footnotetext{
${ }^{8}$ Achmad Romsan, dkk, Pengantar Hukum Pengungsi Internasional, Bandung: Sanic Offset, 2003, hlm. 35

9 M. Rosyidin, 'Kebijakan Cina dalam Krisis Semenanjung Korea: Perspektif Konstruktivis,' Global \& Strategis, vol. 6, no. 1, Januari-Juni, 2011, p. 107.

${ }^{10}$ Alexander Wendt, Social Theory of International Politics, United Kingdom: Cambridge University Press, 1999, p. 1.

${ }^{11}$ Ibid

${ }^{12}$ Alexander Wendt, Anarchy is What State Make of It: The Social Constructruction of Power Politics. International Organization. Vol.46, No.2, (Spring:1992). p. 397.
} 
diartikan "relative stable, role-specific understanding and expectation about self ${ }^{13}$ Wendt juga mengatakan bahwa indentitas merupakan kepentingan dasar dari sebuah negara yang didapat melalui proses mendefinisikan sesuatu. . "Actors do not have a 'portofolio' of interests that they carry around independent of social context; instead they define their in the process of defining situation." 14 Identitas yang mendasari kepentingan inilah yang kemudian diwujudkan dalam perilaku sebuah negara.

\section{Pembahasan}

\section{Latar Belakang Pengungsi Rohingya}

Etnis Rohingya sebenarnya adalah penduduk asli yang telah turun temurun mindiami wilayah Arakan, kawasan terpencil di barat Myanmar yang berbatasan langsung dengan Bangladesh, luas wilayahnya sebesar 14.200 mil persegi. Penduduknya berjumlah 5 juta orang yang terdiri dari dua etnis utama yakni etnis Rohingya yang beragama Islam dan etnis Rakhine/Maghs yang beragama Buddha. Rohingya berasal dari kata Rohang (nama lama dari Arakan). Penduduk di wilayah tersebut sebagian besar berasal dari keturunan Arab yang migrasi pada saat kekhaisaran Mughal yang berkuasa di sub-kontinen India antara tahun 1526 hingga tahun 1858. Ciri khas tersebut terlihat dari tampilan fisik, bahasa, dan kebudayaan yang mengindikasikan adanya hubungan antara etnis Rohingya dengan Chittagonian.

Konflik antara etnis Rohingya dan Rakhine di wilayah Arakan telah berlangsung beberapa dekade lamanya. Pemerintah junta militer Myanmar juga turut melakukan tindak diskriminasi, penyiksaan serta pengusiran terhadap etnis Rohingya yang dianggap bukan bagian dari negara Myanmar, melainkan pendatang asal Bengali yang dituduh telah melakukan gerakan separatis.

Setelah dikeluarkannya UU Kewarganegaraan tahun 1982, etnis Rohingya semakin terpojok setelah status kewarganegaraannya dicabut dan dinyatakan sebagai warga non-kebangsaan (Stateless) atau warga asing. Etnis Rohingya juga menjadi korban diskriminasi dan pelanggaran HAM di negaranya, seperti: tidak

\footnotetext{
${ }^{13}$ Ibid

${ }^{14}$ Ibid,p.398.
} 
diberikannya pengakuan kewarganegaraan, pembatasan dalam mencari lapangan kerja, penyitaan properti, kerja paksa, pembunuhan dan kaum wanita Rohingya sering diperkosa, serta banyak pembakaran rumah dan tempat ibadah. ${ }^{15}$.

Pada masa kepemimpinan Presiden Thein Sein di tahun 2011, kondisi dan situasi etnis Rohingya tidak mengalami perubahan. Penolakan terhadap etnis Rohingya tercermin dalam pernyataan Sein bahwa: "Rohingya are not our people and we have no duty to protect them". Sein menginginkan agar etnis Rohingya berada dalam pengelolaan Komisi Tinggi PBB untuk Pengungsi (UNHCR) atau ditampung oleh negara ketiga. ${ }^{16}$

Tahun 2012, telah terjadi peningkatan eskalasi konflik antara etnis Rakhine dan Rohingya yang dipicu adanya tuduhan pemerkosaan dan pembunuhan terhadap seorang gadis Rakhine oleh para pemuda Rohingya. ${ }^{17}$ Menyusul terjadi penyerangan yang dikoordinasi oleh pemerintah Myanmar, Ethnic Rachine Nasionalist Party, dan pendeta Buddha. Portal berita Aljazeera memberitakan, ada sekitar 5.000 bangunan milik etnis Rohingya rusak akibat tindak represi terebut. Setidaknya sekitar 70 warga etnis Rohingya, termasuk 28 anak-anak terbunuh di Mrauk-U-township. ${ }^{18}$ Pada sensus penduduk saat itu, Pemerintah Myanmar melarang penggunaan istilah Rohingya dan mendaftarkan orang-orang Rohingya sebagai orang Bengali. Pada bulan Maret 2015, Pemerintah Myanmar mencabut kartu identitas penduduk bagi etnis Rohingya yang menyebabkan mereka kehilangan kewarganegaraannya dan hak-hak politiknya. Kartu putih milik etnis Rohingya dinyatakan tidak berlaku sejak 31 Maret 2015. Kartu putih adalah kartu identitas yang diberikan kepada orang-orang yang tinggal di Myanmar namun tidak mendapatkan status resmi sebagai penduduk, penduduk asosiasi, penduduk

15 Diambil dari Pusat Informasi dan Advokasi Rohingya Arakan (PIARA) PAHAM Indonesia, "Rohingya, 101 Data dan Fakta". http://indonesia4rohingya.net/about/

16 Rohingya antar solidaritas ASEAN dan kemanusiaan, 2015, diakses dari http://www.kemlu.go.id/Majalah/ ASEAN\%20 Edisi8-All.pdf, pada tanggal 20 Januari 2016 pukul 20.00 WIB.

${ }^{17}$ B. Brady, 'Burma's Rohingya Muslims Targeted by Buddhist Mob Violence',The Daily Beast (daring),27 Juni 2012, diakses dari http://thedailybeat.com/articles/2013/06/27/burma-srohingya-muslims-targeted-by-buddhist-mob-violence.html, pada tanggal 20 Januari 2016 pukul $15.00 \mathrm{WIB}$.

18 Aljazeera, Report Documents' Rohingya Persecution' (daring), 23 April 2013, diakses dari http:// Aljazeera. com/news/asia-pacific/2013/04/2013421135240814468.html, pada tanggal 20 Januari 2016 pukul 16.00 WIB. 
netral, atau warga negara asing. Kartu putih dikeluarkan oleh rezim sebelumnya pada 1990-an. Saat itu, pemerintah Myanmar meneluarkan Kartu Registrasi Nasional (National Registration Cards) untuk menggantikan kartu sebelumnya yang telah ada, yaitu Kartu Identitas Perserikatan Myanmar (Union of Myanmar Identity Card). Pemegang kartu putih dilarang bepergian tanpa izin pemerintah, harus mendapat izin pemerintah bila ingin menikah dan pemerintah turut andil dalam perencanaan keluarga. Tanpa kartu putih, etnis Rohingya khawatir akan ditangkap dan dipenjara menjelang pemilihan umum di Myanmar. Banyak etnis Rohingya yang melarikan diri dan meminta suaka ke luar negeri, melalui jalur laut dan darat dengan tujuan pertama adalah Malaysia, hal tersebut diketahui berdasarkan penuturan dari korban pengunsi Rohingya. ${ }^{19}$

Para Pengungsi menyerahkan apa saja yang mereka miliki kepada para penyelundup manusia untuk membawa mereka keluar dari Myanmar. ${ }^{20}$ Pelarian dilakukan secara illegal dan banyak yang terjerat sindikat perdagangan manusia dari Thailand. Pemerintah Thailand menemukan adanya bekas kamp-kamp dan kuburan masal yang disinyalir milik etnis Rohingya dan Bangladesh, korban pembunuhan oleh kelompok penyelundup manusia di perbatasan Thailand dan Malaysia. Pemerintah Thailand kemudian melakukan razia besar-besaran yang membuat penyelundup manusia merasa cemas lalu meninggalkan kapal yang bermuatan para pengungsi dengan kondisi tanpa bahan bakar, makanan ataupun air minum dan terkatung-katung di tengah laut tanpa tujuan. Akhirnya kapal-kapal tersebut terdampar di perairan Selat Malaka, dekat dengan wilayah Indonesia dan Malaysia. Kehadiran para pengungsi Rohingya ditolak untuk memasuki wilayah kedaulatan oleh Thailand, Malaysia dan Indonesia. ${ }^{21}$

\section{Sikap Pemerintah Indonesia}

\footnotetext{
${ }^{19}$ Fajar Nugraha, 2015, Malaysia Tolak Imigran Rohingya Kecuali Kapal Mereka Karam, diakses dari http://internasional.metrotvnews.com/read/2015/05/13/125452/malaysia-tolakimigran-rohingya-kecuali-kapal-mereka-karam, pada tanggal 16 januari 2016 pukul 7.00 WIB.

20 Mitra Salima Suryono, 2015, After long ordeal at sea, Rohingya find humanity in Indonesia, diakses dari http://www.unhcr.org/5559efb36.html, pada tanggal 16 januari 2016 pukul 15.00 WIB.

21 Melihat Ganasnya Jalur Pelarian Pengungsi Rohingya, 2015, diakses dari http://blog.act.id/melihat-ganasnya-jalur-pelarian-pengungsi-rohingya/, pada tanggal 19 Januari 2016 pukul 8.00 WIB..
} 
Pada pertengahan bulan Mei 2015, akhirnya setelah sekian minggu terkatungkatung di laut lepas tanpa arah dan tujuan, kapal-kapal rusak tak bermesin yang bermuatan para pengungsi Rohingya terdampat dan memasuki wilayah perairan dekat Aceh Utara. TNI menolak kehadiran para pengungsi etnis Rohingya dengan meningkatkan siaganya serta berupaya menghalau kembali kapal-kapal yang membawa pengungsi Rohingya dan Bangladesh ke tengah laut agar

tidak memasuki wilayah kedaulatan RI. TNI juga melarang keras kepada masyarakat setempat agar tidak membawa para pengungsi ke daratan. ${ }^{22}$

Para nelayan dan warga Aceh Utara beserta tokoh masyarakat setempat merasa merasa iba dan tersentuh rasa kemanusiaannya setelah melihat kondisi para pengungsi yang terdiri dari laki-laki, perempuan dan anak-anak dalam keadaan mengenaskan, tubuh mereka lemah akibat dehidrasi setelah sekian lama dalam kondisi kekurangan logistik serta terkena sengatan sinar matahari yang terik. Para nelayan kemudian bergotong royong menarik kapal-kapal para pengungsi merapat ke darat. Masyarakat yang tidak menghiraukan larangan keras dari TNI, lalu bersama dengan lembaga kemanusiaan bahu membahu menolong mendirikan dapur umum, memberi makan dan mengumpulkan pakaian bekas layak pakai serta menggalang dana bantuan bagi para pengungsi Etnis Rohingya. Mereka kemudian ditempatkan di pengungsian yang tersebar di empat daerah, yaitu Kabupaten Aceh Utara, Kabupaten Aceh Tamiang, Kota Langsa, dan Kabupaten Aceh Timur. ${ }^{23}$

Indonesia saat ini telah banyak menampung pengungsi Rohingya. Oleh karena itu, sikap pemerintah Indonesia bersikeras menolak kehadiran para pengungsian etnis Rohingya yang terdampar di perairan Aceh Utara. ${ }^{24}$. Peningkatan patroli dilakukan dengan tiga kapal dan pesawat pengintai, karena dikhawatirkan kalau para pengungsi kemudian menggunakan modus baru dengan menurunkan para penumpang di laut seperti yang terjadi di Langsa. Kapal-kapal para pengungsi yang ingin merapat dihalau ke tengah laut oleh TNI. Sikap

22 Adiba Hasan, 2015, TNI masih tolak kapal Rohingya, Panglima Aceh serukan penyelamatan, diakses dari http://www.Arrahmah.com/news/2015/05/18/tni-masih-tolak-kapalrohingya-panglima-aceh-serukan-penyelamatan.html, pada tanggal 19 Januari 2016 pukul 15.00 WIB.

${ }^{23}$ Ibid

${ }^{24}$ TNI masih tolak kapal Rohingya, Panglima Aceh serukan penyelamatan, Loc.Cit. 
penolakan serupa juga ditunjukkan oleh Malaysia dan Thailand. Tentu saja ada alasan dari Indonesia yang menolak kehadiran kembali para pengungsi etnis Rohingya.

Direktur Jenderal Hak Asasi Manusia Kementerian Hukum dan Hak Asasi Manusia Mualimin Abdi mengatakan pihaknya sedang mencari cara untuk memulangkan ratusan pengungsi Rohingya yang terdampar di Aceh, karena dapat menimbulkan dampak sosial yang tidak kecil, belum lagi pemerintah harus menyediakan dan memenuhi kebutuhan dasar para pengungsi selama berada di Indonesia yang tentu saja bukan hal kecil, untuk itu pemerintah Indonesia mengeluarkan dana bantuan sebesar Rp. 2,3 milyar bagi para pengungsi Rohingya yang berasal dari APBN. ${ }^{25}$

Kehadiran pengungsi Rohingya di Indonesia bukan kali ini saja. Keberadaan etnis Rohingya asal Myanmar saat ini banyak ditampung di Rumah Detensi Imigrasi (Rudenim) seperti rudenim Belawan, Tanjung Pinang, dan Menado. Selain itu, beberapa pencari suaka dan pengungsi juga berada di luar Rudenim, namun difasilitasi oleh International Organization for Migration (IOM) di beberapa kota seperti Bogor, Jakarta, Makassar, dan Medan. ${ }^{26}$ Bahkan di Bogor, bahkan sudah ada pengungsi Rohingya yang berbaur dan menikah dengan penduduk setempat. Hal tersebut menjadikan status pengungsi Rohingya menjadi semakin tidak jelas.

Saat ini di Indonesia, menurut Menteri Luar Negeri Retno Marsudi paling tidak data sampai per Maret 2015, jumlahnya 11.941, berasal dari 41 negara. Jumlah pengungsi yang cukup banyak tersebut sedang sedang diverifikasi dan menunggu masa penempatan ke negara ketiga. Jumlah pengungsi tersebut bertambah dengan signifikan saat ada 1.346 pengungsi dari Myanmar dan Bangladeh yang masuk ke perairan Indonesia pada Mei $2015 .{ }^{27}$ Sementara itu, data dari UNHCR menyebutkan orang yang menjadi perhatian mereka di Indonesia hingga Juni 2015 tercatat ada 13.188 orang, terdiri dari 5.277 orang

25 Fransiska Ninditya, 2015, Pemerintah gelontorkan $R p$ 2,3 miliar bantu pengungsi Rohingnya, diakses dari http://www.Antaranews.com/berita/498062/pemerintah-gelontorkan-rp23miliar-bantu-pengungsi-rohingnya, pada tanggal 20 Januari 2016 pukul 12.00 WIB.

${ }^{26}$ Rohingya Antara Solidaritas ASEAN dan Kemanusiaan, Loc. Cit.

${ }^{27}$ Kedatangan 1.346 pengungsi Rohingya, pemerintah percepat resettlement, Loc. Cit. 
pengungsi dan pencari suaka sebanyak 7.911 orang. Kebanyakan dari mereka melarikan diri dari konflik pelanggaran HAM di negara asal, seperti Afganishtan, Myanmar, Somalia, Iran dan Iraq. ${ }^{28}$ Pemerintah Indonesia menilai selama ini telah berbaik hati mau menampung para pengungsi yang datang dari berbagai negara, sebab Indonesia bukanlah negara yang ikut meratifikasi Konvensi PBB Tahun 1951 dan Protokol 1967 (tentang pengungsi), oleh sebab itu Indonesia tidak berkewajiban untuk menerima para pengungsi dan tidak ada sanksi yuridis apabila tidak menerima pengungsi. ${ }^{29}$

Atas penolakan terhadap para pengungsi Rohingya, Indonesia mendapat kecamanan dari dalam dan luar negeri. Kecaman berasal dari berbagai lapisan masyarakat dan LSM serta Wakil Ketua DPR RI Fahri Hamzah yang menyayangkan sikap pemerintah dan masyarakat Indonesia yang terkesan tidak peduli terhadap keberadaan sejumlah imigran Rohingya yang terkatung-katung di sejumlah daerah di Indonesia. Menurutnya, penderitaan para pengungsi Rohingya terlihat jelas dan sebagai bangsa yang berprikemanusiaan, Indonesia sepatutnya menolong para pengungsi. DPR juga meminta agar Presiden membuat regulasi sementara sebagai dasar tindakan para pejabat di lapangan, semacam kepres tentang penanganan migran dan pencari suaka. ${ }^{30}$

Beberapa hari kemudian, Indonesia menghadiri rapat konsultasi yang dihadiri oleh para menteri luar negeri dari tiga negara: Indonesia, Malaysia dan Thailand untuk membahas tentang pengungsi Rohingya di Putrajaya (Malaysia) pada tanggal 18 Mei 2015, akhirnya Indonesia dan Malaysia menyatakan kesediaannya untuk menerima para pengungsi Rohingya dan akan membangun tempat penampungan sementara temporary shelter selama satu tahun. Indonesia juga menghimbau negara-negara lain agar berpartisipasi membantu para pengungsi Rohingya, sebab masalah pengungsi Rohingya sudah menjadi masalah regional

28 Tri Wahyuni, 2015, UNHCR:Jumlah Pengungsi di Indonesia Meningkat, diakses dari http://www. cnnindonesia.com/nasional/20150728204221-20-68699/unhcr-jumlah-pengungsi-diindonesia-meningkat/, pada tanggal 20 Januari 2016 pukul 15.00 WIB.

${ }^{29}$ Amanda Puspita Sari, 2015, Indonesia Diimbau Tandatangani Konvensi Pengungsi PBB, diakses dari http://www.cnnindonesia.Com/internasional/20150616195234-106-60423/indonesiadiimbau-tandatangani-konvensi-pengungsi-pbb/,pada tanggal 20 Januasi 2016 pukul 14.00 WIB.

${ }^{30}$ Ahmad Hatim Benarfa, 2015, DPR: Demi Kemanusiaan, Selamatkan Bangsa Rohingya!, diakses dari http://www.teropong- senayan.com/ 10223-dpr-demi-kemanusiaan-selamatkanbangsa-rohingya, pada tanggal 20 Januari 2016 pukul 17.00 WIB. 
yang harus dibahas dengan negara-negara terkait di kawasan dan bahkan internasional.

Atas kesediaan pemerintah Indonesia menampung para pengungsi Rohingya $^{31}$, badan penanggulangan pengungsi dari Perserikatan Bangsa-bangsa (UNHCR) megapresiasi Indonesia yang telah bersedia merawat pengungsi Rohingya dan Bangladesh sebanyak 1.300 orang. ${ }^{32}$ Wakil Presiden Jusuf Kalla juga menegaskan bahwa Pemerintah Indonesia tidak akan menolak kedatangan para pengungsi Rohingya dan mengakui kebijakan awal Indonesia yang menolak, namun kemudian mau menerima kehadiran para pengungsi. ${ }^{33}$ Perubahan sikap Indonesia jelas terlihat karena adanya kekuatan norma HAM dari masyarakat lokal dan identitas Indonesia yang akhirnya mengkonstruksikan Indonesia menjadi mau menerima para pengungsi yang memiliki kesamaan identitas, yakni sebagai korban dari tindak pelanggaran HAM di negara asalnya Myanmar. Norma HAM telah mendorong Indonesia untuk mengenyampingkan problem sosial yang akan timbul dengan banyaknya pengungsi yang berada di tanah air. Sebagai negara penerima, Indonesia wajib memberikan tempat tinggal, makanan, obatobatan dan kehidupan yang layak bagi para pengungsi, padahal Indonesia bukanlah negara yang meratitikasi Konvensi PBB tahun 1951 tentang pengungsi dan Protokol Tahun 1967, oleh karenanya Indonesia tidak berkewajiban untuk menerima para pengungsi di wilayah negaranya. Namun, karena masalah pengungsian ini telah diterima oleh Majelis PBB sebagai sebuah resolusi yang di dalamnya terdapat seruan agar semua negara anggota PBB memberikan perlindungan internasional kepada pengungsi dan mencari solusi permanen bagi masalah pengungsi. Sehingga apabila ada yang mengaku pengungsi atau pencari suaka masuk ke Indonesia, maka pemerintah melaksanakan resolusi tersebut dengan bekerja sama, yaitu dengan cara memberitahukannya kepada UNHCR

\footnotetext{
${ }^{31}$ Malaysia dan Indonesia Setuju Tampung Pengungsi Rohingya, Loc. Cit.

${ }^{32}$ Natalia Santi, 2015, Menteri Retno Bantah Indonesia Tolak Pengungsi Rohingya, diakses dari http://dunia.Tempo.co/read/news/2015/05/18/118667216/menteri-retno-bantah-indonesiatolak-pengungsi rohingya, pada tanggal 20 Januari 2016 pukul 16.00 WIB.

${ }^{33}$ Icha Rastika, 2015, Wapres:TNI Tidak Boleh Lagi Tolak Pengungsi Rohingya, diakses pada http://nasional.kompas.com/read/2015/05/20/17114371/Wapres.TNI.Tidak.Boleh.Lagi.Tolak.Peng ungsi.Rohing- ya, pada tanggal 20 Januari 2016 pukul 17.30 WIB.
} 
(United Nations High Commissioner for Refugees) yang merupakan badan internasional komisioner tinggi PBB untuk Pengungsi dengan bertujuan untuk melindungi dan memberikan bantuan kepada pengungsi berdasarkan permintaan sebuah pemerintahan atau PBB kemudian untuk mendampingi para pengungsi tersebut dalam proses pemindahan tempat menetap mereka ke tempat yang baru. ${ }^{34}$

Dengan bertambahnya jumlah pengungsi yang signifikan, Indonesia menggelontorkan dana bantuan sebesar Rp.2,3 milyar dari APBN untuk para pengungsi, padahal kondisi ekonomi Indonesia sendiri tengah mengalami krisis ekonomi. Identitas telah mempengaruhi kebijakan Indonesia dalam hal kasus pengungsi Rohingya yang terdampar dan diselamatkan oleh masyarakat Aceh menunjukkan bahwa norma HAM yang dijunjung tinggi oleh masyarakat Indonesia, khususnya masyarakat Aceh juga mampu mendesak pemerintah untuk merubah sikap yang semula menolak para pengungsi, menjadi bersedia menerima. Indonesia sebagai bagian dari masyarakat internasional tidak terlepas dari identitas dan share idea tentang HAM yang disepakati bersama dan telah menjadi identitas, setelah sekian lamanya norma HAM mengalami pasang surut dari masa ke masa kepemimpinan. Implementasi dari HAM di Indonesia baru benar-benar terwujud setelah tumbangnya Orde Baru yang digantikan dengan era reformasi, seperti : Indonesia mengadakan referendum kebebasan pada rakyat Timor Timur (propinsi ke-27) pada 30 Agustus 1999, yang berujung dengan berdirinya negara Timor Leste secara resmi pada 20 Mei 2002; Dikeluarkannya Undang-Undang anti diskriminasi: Pemilihan kepala negara dan kepala daerah secara langsung di pilih rakyat sejak era pemerintahan Presiden Susilo Bambang Yudhoyono; dsb. Sebagai negara yang sebagai negara beridentitas demokratis dan menjunjung tinggi HAM, segala tindakan yang dianggap bertentangan dengan norma HAM atau tidak mencerminkan identitas bangsa tentunya akan menuai kecaman, baik dari lokal maupun internasional.

\section{Penutup}

Sikap Indonesia menerima para pengungsi Rohingya karena adanya kesamaan identitas sebagai negara yang menjunjung tinggi norma HAM dan

\footnotetext{
${ }^{34}$ UNHCR di Indonesia, diakses dari http://www.unhcr.or.id/id/tentang-unhcr, pada tanggal 20 Januari 2016 pukul 18.00 WIB.
} 
pengungsi Rohingya adalah korban dari pelanggaran HAM di negara asalnya Myanmar. Sebagai bagian dari masyarakat internasional, Indonesia telah menunjukkan sikap yang perduli dan mau menampung para pengungsi Rohingya, padahal Indonesia bukanlah salah satu negara yang menandatangani dan meratifikasi Konvensi PBB tahun 1951 (tentang pengungsi), bisa saja bila Indonesia tidak mau menerima pengungsi di wilayahnya dan tidak akan terkena sanksi yuridis.

\section{DAFTAR PUSTAKA}

After long ordeal at sea, Rohingya find humanity in Indonesia. http://www.unhcr.org/ 5559efb36.html.

Aljazeera. Report Documents' Rohingya Persecution' (daring). http://Aljazeera. com/news/asia-pacific/2013/04/2013421135240814468.html.

B. Brady.'Burma's Rohingya Muslims Targeted by Buddhist Mob Violence',The Daily Beast (daring). http://thedailybeat.com/articles/2013/06/27/burma-srohingya-muslims-targeted-by-buddhist-mob-violence.html.

Di Selat Malaka, Masih 8000-an Pengungsi Masih Terkatung katung. http://www.teropong senayan.com/10725-di-selat-malaka-masih-8000-anpengungsi-masih-terkatung katung/.

DPR: Demi Kemanusiaan, Selamatkan Bangsa Rohingya!. http://www.teropongsenayan.com/ 10223-dpr-demi-kemanusiaan-selamatkan-bangsa-rohingya.

Griffiths, Martin . Martin Steven C. Roach. dan M. Scott Solomon. (2009). "Fifty Key Thinkers in International Relations Second Edition" (2nd ed). New York: Routledge.

Indonesia Diimbau Tandatangani Konvensi Pengungsi PBB. http://www.cnn indonesia.com /internsional/20150616195234-106-60423/indonesia-diimbautandatangani-konvensi-pengungsi-pbb/. 
Kamus Besar Bahasa Indonesia. (1995). Departemen Pendidikan dan Kebudayaan. Jakarta: Balai Pustaka.

Kedatangan 1.346 pengungsi Rohingya, pemerintah percepat resettlement. http://www. rappler.com/world/regions/asia-pacific/indonesia/bahasa/93694kedatangan-pengungsi-rohingya-pemerintah-percepat-resettlement.

Malaysia dan Indonesia Setuju Tampung Pengungsi Rohingya. http://www.dw.com/id/ malaysia-dan-indonesia-setuju-tampung-pengungsirohingya/a-18462889/.

Malaysia Tolak Imigran Rohingya Kecuali Kapal Mereka Karam. http://internasional. Metrotvnews.com/read/2015/05/13/125452/malaysiatolak-imigran-rohingya-kecuali-kapal mereka-karam.

Melihat Ganasnya Jalur Pelarian Pengungsi Rohingya. http://blog.act.id/melihatganasnya-jalur-pelarian-pengungsi-rohingya/.

Menteri Retno Bantah Indonesia Tolak Pengungsi Rohingya. http://dunia.Tempo.co/read/ news/2015/05/18/118667216/menteri-retnobantah-indonesia-tolak-pengungsi-rohingya.

Pemerintah Akan Pulangkan Pengungsi Rohingya. http://nasional.tempo.co/read/news/ 2015/05/19/058667533/pemerintah-akanpulangkan-pengungsi-rohingya.

Pemerintah gelontorkan Rp2,3 miliar bantu pengungsi Rohingnya. http://www. antaranews.com/berita/498062/pemerintah-gelontorkan-rp23-miliar-bantupengungsi rohingnya.

Pusat Informasi dan Advokasi Rohingya Arakan (PIARA) PAHAM Indonesia. “ Rohingya,101 Data dan Fakta”. http://indonesia4rohingya.net/about/

Rohingya antar solidaritas ASEAN dan kemanusiaan. http://www.kemlu.go.id/Majalah/ ASEAN\%20Edisi8-All.pdf.

Romsan, Achmad dkk. (2003). Pengantar Hukum Pengungsi Internasional. Bandung: Sanic Offset 
Rosyidin, M. (2011, Januari-Juni) 'Kebijakan Cina dalam Krisis Semenanjung Korea: Perspektif Konstruktivis,’. Global \& Strategis. 6, (1).

TNI masih tolak kapal Rohingya, Panglima Aceh serukan penyelamatan. http://www.Ar- rahmah.com/news/2015/05/18/tni-masih-tolak-kapalrohingya-panglima-aceh-serukan penyelamatan.html.

UNHCR di Indonesia. http://www.unhcr.or.id/id/tentang-unhcr.

UNHCR. http://www.unhcr.org/pages/49c3646c2.html

UNHCR: Jumlah Pengungsi di Indonesia Meningkat. http://www.cnnindonesia.com/nasio-nal/20150728204221-20-68699/unhcrjumlah-pengungsi-di-indonesia meningkat/.

Wapres: TNI Tidak Boleh Lagi Tolak Pengungsi Rohingya, http://nasional.kompas.com/ $\mathrm{read} / 2015 / 05 / 20 / 17114371 /$ Wapres.TNI.Tidak.Boleh.Lagi.Tolak.Pengungsi.R ohingya.

Wendt, Alexander. (1992, Spring). Anarchy is What State Make of It: The Social Constructruction of Power Politics. International Organization. 46, (2).

Wendt, Alexander. (1999). Social Theory of International Politics. United Kingdom: Cambridge.

What is a refugee. http://www.unhcr.or.id/id/siapa-yang-kami-bantu/pengungsi. 